\title{
Assessment of the frequency of hormonal disorders of the gonads and bone mineral density among women treated for anorexia nervosa in adolescence
} Ocena częstości występowania zaburzeń funkcji hormonalnej gonad i gęstości mineralnej kości u kobiet leczonych z powodu jadłowstrętu psychicznego w okresie adolescencji

\author{
${ }^{1}$ Magdalena Wszołek, ${ }^{2}$ Karolina Ziora-Jakutowicz, ${ }^{3}$ Piotr Gorczyca, ${ }^{4}$ Katarzyna Rojewska, \\ ${ }^{5}$ Katarzyna Ziora
}

${ }^{1}$ Individual Specialist Medical Practice, Poland

${ }^{2}$ Department of Genetics, Institute of Psychiatry and Neurology, Warsaw, Poland, Polska

${ }^{3}$ Department of Psychiatry, Faculty of Medical Sciences in Zabrze, Medical University of Silesia in Katowice, Poland

${ }^{4}$ Pediatric Endokcrinology, Public Clinical Hospital No.1 in Zabrze, Poland, Polska

${ }^{5}$ Department of Paediatrics, Faculty of Medical Sciences in Zabrze, Medical University of Silesia in Katowice, Poland

\begin{abstract}
Introduction: There are very few studies evaluating the activity of gonads in women treated for anorexia nervosa (AN) in adolescence, and reports on the bone mineral density in such patients are divergent. Objective Assessment of the incidence of gonadal hormonal function disorders and reduction of bone mineral density in women treated for AN in adolescence.

Material and methods: Out of 97 women who had participated in a survey study, 56 reported personally to the clinic. Their somatic condition, body weight, and BMI were evaluated, as well as levels of oestradiol, LH, FSH in blood serum were determined and DEXA scans were performed.

Results: The average period of hospitalisation until the time of the study was $7.08 \pm 4.47$ years. BMI was as follows: $20.01 \pm 3.6 \mathrm{~kg} / \mathrm{m}^{2}$. $25 \%$ women were still sick, $75 \%$ were considered cured. In $17.9 \%$ of the study subjects hypogonadotropic hypogonadism was diagnosed. Abnormal results of the densitometric scan were confirmed in $85.7 \%$ of the study subjects. In the group of women with normal body weight only $19 \%$ had normal levels of bone mineral density.

\section{Conclusions:}

1. In almost $18 \%$ of women treated for AN in adolescence, disorders of the hormonal function of gonads persist, despite normal body weight in $50 \%$ of them.

2. Bone mineral density is reduced in most women treated for $\mathrm{AN}$, which indicates the need to monitor the condition of the bones, an early introduction of prevention of osteopenia and osteoporosis since the onset of $\mathrm{AN}$ in order to prevent bone fractures in adulthood.
\end{abstract}

Key words:

anorexia nervosa, bone density, long-term follow-up, hypogonadotrophic hypogonadism.

\section{Introduction}

Anorexia nervosa (AN) is a psychosomatic syndrome consisting in the patient's desire to lose weight, even at the expense of extreme emaciation, a co-existing fear of putting on weight, and distorted assessment of the patient's own body. Most often, this condition has its onset in adolescence. AN may have dire consequences, such as organ-related and/or mental complications [1]. Patients suffering from AN present with numerous disorders on the part of the endocrine system, which result from the adaptation to chronic starvation, malnutrition, and chronic stress. These hormonal adaptation mechanisms aim at maintaining homeostasis and euglycemia in the human body; however, they also have a negative effect on bone tissue mineralisation $[1,2]$. 
One of the adaptation mechanisms is hypogonadotropic hypogonadism, one of the most frequently observed hormonal disorders in the acute phase of AN, characterised by a delay in puberty and primary or secondary amenorrhea. A lower LH level in serum is observed in as many as $80.8 \%$ of girls with AN [3]. Lowered blood oestradiol levels, on the other hand, detected in $50 \%$ of girls with AN [3], constitute one of important factors triggering osteoporosis [4]. Oestrogens pay a key role in maintaining skeletal homeostasis, participating in bone formation and bone resorption mechanisms [5]. It is known that ca. $90 \%$ of bone mass is reached at ca. 15 years of age, and the peak bone mass is observed only between the $17^{\text {th }}$ and $22^{\text {nd }}$ year of age. Since the peak incidence of AN falls on a period which is fundamental for reaching the peak body mass, these patients face a high risk of osteoporosis, and in consequence pathological bone fractures. The risk of reduced mineral density of bones in patients suffering from anorexia nervosa is additionally increased due to deficiencies of substrates necessary for bone tissue forming in puberty, such as proteins, calcium, vitamin D, caused by starvation. Reduced levels of IGF-1, DHEA, testosterone in blood and hypercortisolaemia in AN patients additionally aggravate the threat of osteoporosis [6-8]

Authors who analyse distant treatment results in AN patients pay special attention to the fates of such individuals as far as their recovery is concerned, investigating not only the frequency of relapses and remissions, duration of somatic and mental symptoms of the disease, but also the ability to reproduce and produce offspring. Many authors believe that besides an increase of body weight and resolution of psychological symptoms, the return of regular menses constitutes another recovery criterion [9-12]. It is not always possible to predict when it will happen - clinical observations indicate that the return of menses in anorectic women depends on numerous factors, not only on weight gain or body fat content [13-17].

The available literature contains only few studies assessing the hormonal activity of gonads in women treated for anorexia nervosa in adolescence $[15,16]$. Some authors investigated the ability to restore the reproductive function of gonads in such patients on the basis of the return of menses [13]. Others, on the other hand [14] searched for prognostic factors fostering the return of menses in AN patients. The Polish literature lacks studies devoted to this topic.

There are research results pointing to an increased risk of osteoporosis in patients treated for anorexia nervosa in childhood or youth [18-23]. Reports on the frequency of osteopenia and osteoporosis in women with $\mathrm{AN}$, however, are divergent.

The objective of this paper is to evaluate the incidence of disorders of the hormonal function of gonads and of a decrease in the bone mineral density in women treated for anorexia nervosa in adolescence.

\section{Material and methods}

This study constitutes a continuation of the research we conducted in the subject of long-term treatment results in women suffering from anorexia nervosa in adolescence (publication in progress). All the subjects suffered from the restrictive type of AN in childhood [24].

The questionnaire developed for the purposes of the study contained questions concerning long-term health status of the patients after hospitalisation due to $A N$ in childhood. All the study subjects filled out the questionnaire, providing information on all their hospitalisations, outpatient treatments, current complaints, comorbidities, use of medications, as well as menstruations and children. The results of the questionnaire were presented in the previous publication.

On the basis of medical histories of the patients covering the period of their hospitalisations, the following data were obtained: age at the time of admission, body weight, BMI, BMISDS, degree of malnutrition (Cole's index), and duration of amenorrhea prior to hospitalisation (Table I).

Out of 97 women taking part in the study, 56 (average age: $22.53 \pm 4.11$ years) reported personally to the clinic for hormone tests (oestradiol, LH, FSH) and bone density scans (DEXA scans) after filling out the questionnaire. This study covered exclusively those women who reported personally in the clinic. None of them had been on any contraceptives over the three months preceding the study.

In all the study subjects, their somatic condition, body weight, and BMI were evaluated. A criterion of recovery from anorexia nervosa was a normal body weight, return of menstruations, no indications for continuing psychotherapy.

In all the study subjects a blood sample was examined in order to determine the levels of sex hormones (oestradiol, LH, $\mathrm{FSH}$ ) in blood serum. The tests were carried out in the follicular phase. The levels were determined by means of eletrochemiluminescence (ECLIA by Roche) with the application of the Cobas 6000 apparatus in the Laboratory of the Clinical Hospital No. 1 in Zabrze.

Subsequently, densitometry scans were also performed, by means of dual energy X-ray absorptiometry (DEXA) in order to evaluate the bone mineral density (BMD) $\left(\mathrm{g} / \mathrm{cm}^{2}\right)$ of the spine (s-BMD) and total body (TB-BMD) by means of the LUNARDPX-L apparatus, USA, in the Densitometry Laboratory of the Independent Public Clinical Hospital No. 1 in Zabrze. The acquired test results were juxtaposed with the diagnostic criteria of osteopenia ( $-1.0 \mathrm{SD} \geq \mathrm{T}$-score $>-2.5 \mathrm{SD}$ ) and osteoporosis (T-score $\leq-2.5$ SD) [25]

The Bioethics Committee of the Medical University of Silesia in Katowice issued a permission to conduct the study (KNW/0022/KB1/3/11 dated 18/01/2011).

\section{Statistical methods}

A relevant database was prepared in a spreadsheet in Microsoft Excel. Statistical calculations were carried out in MedCalc ver. 18.2.1. The statistical calculations assumed the level of statistical significance $a=0.05$. The following descriptive statistics were calculated for all the numerical variables: arithmetic mean, median, minimum value, maximum value, lower and upper quartile, standard deviation (SD), statistical error (SEM), variance, 95\% confidence interval around the mean and median. The compliance of their distribution with the normal 
Table I. Characteristics of the women examined at the time of diagnosis of anorexia nervosa (data from the period of childhood hospitalization obtained from the history of the disease)

\begin{tabular}{ll}
\hline \multirow{2}{*}{ Parameter } & $n=56$ \\
\cline { 2 - 2 } & Average \pm SD (Min.-Max.) \\
\hline Age (years) & $15.45 \pm 1.55(11.5-17.8)$ \\
\hline Weight $(\mathrm{kg})$ & $39.96 \pm 6.86(28-56.9)$ \\
\hline Growth $(\mathrm{cm})$ & $160.63 \pm 6.44(143.5-172)$ \\
\hline BMl $\left(\mathrm{kg} / \mathrm{m}^{2}\right)$ & $15.37 \pm 2.14(11.3-21.7)$ \\
\hline BMI-SDS & $-2.67 \pm 1.15(-5.58-0.611)$ \\
\hline Cole's Index (\%) & $76.38 \pm 10.38(55-105)$ \\
\hline $\begin{array}{l}\text { The duration of amenorrhoea } \\
\text { before hospitalization (months) }\end{array}$ & $9.55 \pm 6.93(336)$ \\
\hline
\end{tabular}

Table II. Characteristic of the group of women examined (data obtained prospectively years after hospitalization due to anorexia nervosa)

\begin{tabular}{ll}
\hline Parameter & $n=56$ \\
\cline { 2 - 2 } & Average \pm SD (Min.-Max.) \\
\hline $\begin{array}{l}\text { Time since hospitalization } \\
\text { (years) }\end{array}$ & $7.08 \pm 4.47(1.5-16.6)$ \\
\hline Age (year) & $22.53 \pm 4.11(17.3-31)$ \\
\hline Weight $(\mathrm{kg})$ & $53.85 \pm 12.06(31.5-114)$ \\
\hline Weight gain $(\mathrm{kg})$ & $13.89 \pm 12.26(-11.9-73.3)$ \\
\hline Growth $(\mathrm{cm})$ & $163.53 \pm 6.32(152-177)$ \\
\hline Height gain $(\mathrm{cm})$ & $2.9 \pm 5.19(0-32.5)$ \\
\hline BMI $\left(\mathrm{kg} / \mathrm{m}^{2}\right)$ & $20.01 \pm 3.6(13.6-37.2)$ \\
\hline BMI difference $\left(\mathrm{kg} / \mathrm{m}^{2}\right)$ & $4.65 \pm 4.02(-4.5-23.1)$ \\
\hline BMI-SDS & $0.61 \pm 1.63(-4.2-3.05)$ \\
\hline BMI-SDS difference & $2.05 \pm 1.79(-2.72-5.94)$ \\
\hline
\end{tabular}

Weight gain the difference between actual weight and weight during hospitalization

Height gain the difference between the actual height and the height during hospitalization

$\mathrm{BMI}$ difference the difference between the current BMI and the BMI during hospitalization

SDS-BMI difference the difference between the current BMI-SDS and BMI-SDS during the hospitalization distribution was checked. The compliance assessment applied the D'Agostino-Pearson test.

\section{Results}

Tables I and II present details on the age and anthropometric parameters (body weight, BMI, BMI-SDS, Cole's index) of 56 examined women from the period of hospitalisation, and data obtained years after, during the study carried out in the clinic.

The average age of the examined girls at the time of the AN diagnosis during their stay in the clinic was $15.45 \pm 1.55$ years (range: 11.5-17.8 years), whereas years after it was 22.53 \pm 4.11 years (range: $17.3-31$ years). The average time between hospitalisations and this study was $7.08 \pm 4.47$ years (range: 1.5-16.6 years).

The average body weight in the study subjects was 53.85 $\pm 12.06 \mathrm{~kg}$ (range: $31.5-114 \mathrm{~kg}$ ), the average height was 163.53 $\pm 6.32 \mathrm{~cm}$ (range: $152-177 \mathrm{~cm}$ ), the average BMI was BMl $20.01 \pm 3.6 \mathrm{~kg} / \mathrm{m}^{2}$ (range: $13.6-37.2 \mathrm{~kg} / \mathrm{m}^{2}$ ). The weight gain after hospitalisation was $13.89 \pm 12.26 \mathrm{~kg}$ on average (range: $-11.9-73.3 \mathrm{~kg}$ ). The difference between the current BMI and the $\mathrm{BMI}$ from the time of hospitalisation was $4.65 \pm 4.02 \mathrm{~kg} / \mathrm{m}^{2}$ on average (range: $13.6-37.2 \mathrm{~kg} / \mathrm{m}^{2}$ ). The standard deviation for BMI (BMI-SDS) was $-0.61 \pm 1.63$ on average during the study, whereas the difference between the current BMI-SDS and the BMI-SDS in the period of hospitalisation was $2.05 \pm 1.79$ on average (Table II).

The studied group demonstrated that $25 \%$ of the study subjects (14 women) were still sick with anorexia nervosa, whereas $75 \%$ (42 women) were considered cured.

The majority of the studied women (82.2\%) did not report any menstrual disorders as of the time of the study. Ten women, on the other hand (17.9\%), reported persistent amenorrhea, even though in $50 \%$ of them their body weight was within the normal limits. Two of them reported primary amenorrhea, and eight - secondary amenorrhea. Secondary amenorrhea was more frequently detected at the onset of the disease as of hospital admission (in 91\% women) than primary amenorrhea (in 8.9\%). However, the share of women who did not menstruate in adulthood was higher in those with primary amenorrhea (40\%) than in those with secondary amenorrhea (15.7\%) in medical history. All the women with the primary amenorrhea at the onset of AN were not older than 16 years of age.

The average levels of oestradiol, $\mathrm{LH}$, and FSH in blood serum in the patients during hospitalisations in childhood were as follows: $15.23 \pm 17.61 \mathrm{pg} / \mathrm{ml}$ (range: 3.99-85.4 pg/ml); $1.09 \pm 2.28 \mathrm{mlU} / \mathrm{ml}$ (range: $0.01-15.64 \mathrm{mlU} / \mathrm{ml}$ ), and 3.04 $\pm 2.61 \mathrm{mlU} / \mathrm{ml}$ (range: 0.01-10.13), respectively (Table III). Hypogonadotropic hypogonadism (lowered LH and oestradiol levels in blood serum) was diagnosed in $87,5 \%$ of the girls in this group.

On the other hand, in the group of women examined years after hospitalisations, hypogonadotropic hypogonadism was presented in $17.9 \%$ of women. The average levels of oestradiol, LH, and FHS in blood serum were, respectively: 72.11 $\pm 95.03 \mathrm{pg} / \mathrm{ml}$ (range: $4.99-395.4 \mathrm{pg} / \mathrm{ml}$ ); $8.23 \pm 10.23 \mathrm{mlU} / \mathrm{ml}$ (range: $0.09-51.89 \mathrm{mlU} / \mathrm{ml}$ ), and FSH $5.21 \pm 2.46 \mathrm{mlU} / \mathrm{ml}$ 
Table III. The results of tests performed during hospitalization $(n=56)$

\begin{tabular}{llll}
\hline Parameter & \multicolumn{3}{l}{ The results of hormone levels in the serum } \\
\cline { 2 - 4 } & $\begin{array}{l}\text { Average } \pm \text { SD } \\
\text { (Min.-Max.) }\end{array}$ & $\begin{array}{l}\text { Results } \\
\text { a) decreased } \\
\text { b) elevated }\end{array}$ & $\begin{array}{l}\text { Percentage } \\
\text { of results }\end{array}$ \\
& & c) correct & \\
\hline $\mathrm{FSH}$ & $3.04 \pm 2.61$ & a) 31 & a) 55.4 \\
$(\mathrm{mlU} / \mathrm{ml})$ & $(0.01-10.13)$ & b) 0 & b) 0 \\
& & c) 25 & c) 44.6 \\
\hline $\mathrm{LH}$ & $1.09 \pm 2.28$ & a) 49 & a) 87.5 \\
$(\mathrm{mlU} / \mathrm{ml})$ & $(0.01-15.64)$ & b) 1 & b) 1.8 \\
& & c) 6 & c) 10.7 \\
\hline $\begin{array}{l}\text { Oestradiol } \\
(\mathrm{pg} / \mathrm{ml})\end{array}$ & $15.23 \pm 17.61$ & a) 38 & a) 67.8 \\
& $(3.99-85.4)$ & b) 1 & b) 1.8 \\
\hline
\end{tabular}

(range: $0.18-14.07 \mathrm{mlU} / \mathrm{ml}$ ) (Table IV). In eight women an elevated level of LH above the normal limits was detected, and in one woman an elevated level of FSH in blood was confirmed.

On the basis of the DEXA scan of the spine carried out in the group of women studied years after in the clinic it was demonstrated that the average T-SCORE was $-1.29 \pm 1.35$, whereas Z- SCORE was $-1.09 \pm 1.43$. The average value of T-SCORE in the total body DEXA scan was $-1.79 \pm 1.19$, whereas Z-SCORE was $-1.69 \pm 1.24$ (Table V).

Abnormal results of the DEXA scan pointing to body mineral density (BMD) disorders were demonstrated in $85.7 \%$ of the study subjects (48 women), 51.8\% of whom (29 women) satisfied the diagnostic criteria for osteopenia, and 33.9\% (19 women) satisfied the diagnostic criteria for osteoporosis. Normal bone mineral density levels were confirmed only in $14.3 \%$ of women. Analysing exclusively women with a normal body weight, it was demonstrated that only $19 \%$ of them had normal body mineral density levels.

\section{Discussion}

Anorexia nervosa is a chronic condition with long-term complications, a reduction in terms of reproductive capacity being one of them. The return of spontaneous, regular menstruation in AN patients constitutes one of important symptoms testifying to the ability to produce offspring. Clinical observations point to the fact that the treatment does not succeed in obtaining normal hormonal activity of gonads in all anorexia nervosa patients $[13,16]$. Our study confirms it. We demonstrated that 7 years after falling sick on average, nearly $18 \%$ of women treated for AN in adolescence still have menstrual disorders caused by hypogonadotropic hypogonadism.

Similar observations were made by other authors $[13,16]$. Japanese authors studied the reproductive activity in 21 AN
Table IV. The results of tests performed years after hospitalization $(n=56)$

\begin{tabular}{llll}
\hline Parameter & \multicolumn{3}{l}{ The results of hormone levels in the serum } \\
\cline { 2 - 4 } & $\begin{array}{l}\text { Average } \pm \text { SD } \\
\text { (Min.-Max.) }\end{array}$ & $\begin{array}{l}\text { Results } \\
\text { a) decreased } \\
\text { b) elevated }\end{array}$ & $\begin{array}{l}\text { Percentage } \\
\text { of results }\end{array}$ \\
& & c) correct & \\
\hline $\mathrm{FSH}$ & $5.21 \pm 2.46$ & a) 13 & a) 23.2 \\
$(\mathrm{mlU} / \mathrm{ml})$ & $(0.18-14.07)$ & b) 1 & b) 1.8 \\
& & c) 42 & c) 75 \\
\hline $\mathrm{LH}$ & $8.23 \pm 10.26$ & a) 10 & a) 17.9 \\
$(\mathrm{mlU} / \mathrm{ml})$ & $(0.09-51.89)$ & b) 8 & b) 14.2 \\
& & c) 38 & c) 67.9 \\
\hline Estradiol & $72.11 \pm 95.03$ & a) 17 & a) 30.4 \\
$(\mathrm{pg} / \mathrm{ml})$ & $(4.99-395.4)$ & b) 0 & b) 0 \\
& & c) 39 & c) 69.6 \\
\hline
\end{tabular}

Table V. DEXA results after years in the study group $(n=56)$

\begin{tabular}{ll}
\hline & Average \pm SD (Min.-Max.) \\
\hline T-SCORE KR & $-1.29 \pm 1.35(-5-1.4)$ \\
\hline Z-SCORE KR & $-1.09 \pm 1.43(-5-2.8)$ \\
\hline T-SCORE TB & $-1.79 \pm 1.19(-5-0.4)$ \\
\hline Z-SCORE TB & $-1.69 \pm 1.24(-5-0.9)$ \\
\hline
\end{tabular}

KR - spine; TB - total body

patients 10 years after falling ill. They demonstrated that the incidence of amenorrhea in these patients after reaching normal body weight was $19 \%$ and was higher than in the general population of women (6\%). Nevertheless, they observed that the incidence of pregnancy in women after AN was similar to the one noted in the normal population. Changes in terms of body weight in women with persistent amenorrhea did not differ significantly from changes in terms of body weight in women who had started to menstruate again [13].

Other authors when presenting their results of treatment of AN patients demonstrated that menstruation had returned in $28 \%$, or in $92 \%$ of patients in another study. According to the authors referred to above [13], such divergent results could be caused by different diagnostic criteria, different therapies, different follow-up duration, and differences in terms of defining recovery criteria.

Jacoangeli et al. [16] when studying a group of 250 women with AN treated on an outpatient basis for 2 years, in whom body weight increased and did not change for at least 6 months 
$\left(\mathrm{BMI} \geq 18 \mathrm{~kg} / \mathrm{m}^{2}\right)$, confirmed amenorrhea in $14 \%$ of women. Our study covered a different, smaller group of women, hospitalised due to ill health.

In the majority of patients (91\%) secondary amenorrhea was confirmed at the moment of falling ill, and patients with primary amenorrhea were premenarchal. Dempfle et al. [14] assessed predictive factors of the return of menstruation in 172 AN patients during a 12-month-long follow-up period. Like us, they demonstrated that as of the moment of falling ill secondary amenorrhea appeared in the majority of the patients. The other study subjects (36 patients: 20.9\%) with primary amenorrhea were either premenarchal (31 patients), like our patients, or they had primary amenorrhea $>16$ years of age (5 patients). After excluding from the study 20 patients who during the follow-up period were on hormonal contraception, the authors demonstrated that menstruation spontaneously resumed in $47 \%$ of patients, whereas 80 patients were still not menstruating (53\%). Menstruation did not return in any of the patients with primary amenorrhea, and it did return in three premenarchal patients with amenorrhea. We conducted the study in the group of women after a much longer follow-up period than the authors referred to above $-1.5-16.5$ years after falling ill. We concluded that patients with the onset of anorexia nervosa in the premenarchal period were at higher risk of prolonged amenorrhea than the ones with secondary amenorrhea, even despite body weight normalisation.

We studied the hormonal function of gonads, assessing levels of sex hormones in blood serum during the study and retrospectively on the basis of results obtained from the patients' medical histories. This allowed for an objective evaluation of the ovarian function. Other authors based exclusively on information obtained from the study subjects on their menstruation, pregnancies, and offspring [13, 14]. Still other authors [15-17] also determined levels of sex hormones in blood when looking for factors influencing the return of normal function of gonads in women with AN. Golden et al. [15], during a study of adolescent girls and women with anorexia nervosa (average age: 16.9; range: 12-24) concluded that what is necessary for menstruation to return is the body weight gain (to the value reaching ca. $90 \%$ of the ideal body weight) and the return of the hypothalamic-pituitary-gonadal function, which is best evaluated by determining the level of oestradiol in blood serum. According to these authors, the return of menstruation does not depend on the body fat content.

Deliberations devoted to predictive factors fostering the return of menstruation with hypothalamic amenorrhea have been the subject matter of research conducted by other authors, too [14-17]. Already in 1974, Frisch and McArthur [26] put forward a hypothesis that in women in a state of malnutrition menstruation returns only after achieving a critical body weight, reflecting the critical body fat content.

Golden et al. [15] demonstrated that in AN patients menstruation returned only after increasing body weight by at least $2.05 \mathrm{~kg}$ beyond the body weight when menstruation stopped. Winkler et al. [27] demonstrated that positive predictors for the return of menstruation were both $\mathrm{BMI}$ and the percentage of the adipose tissue measured by means of bone densitometry. In their opinion, the method of analysing the body composition by means of the DEXA scan did not have any higher value than the $\mathrm{BMI}$ evaluation in predicting the return of menstruation in AN patients.

Jacoangeli et al. [16] analysed the body composition of 20 women suffering from anorexia nervosa (age: 16.5-25) by means of the DEXA scan, measured their physical activity (minutes of exercise a day), and evaluated levels of hormones in blood (PRL, GH, 17ß-oestradiol, LH, FSH, TSH, FT3, FT4) and free cortisol in the 24-h urine collection. In women with amenorrhea, the percentage of the adipose tissue was $22.23 \pm 5.32 \%$, whereas in women with regular periods it was $26.03 \pm 9.1 \%$. Women with amenorrhea demonstrated a significantly higher physical activity (45 $\pm 38 \mathrm{~min} /$ day) as compared to eumenorrheic patients (14 $\pm 20 \mathrm{~min} /$ day) $(\omega=0.018)$. In amenorrheic patients the excretion of cortisol in urine was significantly higher $(58.14 \pm 0.4 \mu \mathrm{g} / 24 \mathrm{~h})$ than in the group of eumenorrheic patients $(15.91 \pm 9.5 \mu \mathrm{g} / 24 \mathrm{~h})(\mathrm{p}=0.02)$. They concluded that appropriate body composition and quantity of the adipose tissue is a necessary, but not sufficient condition for regular menstrual cycles to return. The return of menstrual cycles may depend on other factors studied by other researchers, such as excretory patterns of leptin or adrenal function.Dempfle et al. [14] believe that such factors as longer hospitalisation, higher BMI prior to the disease, and body weight lower than the target value at the time of hospital discharge may affect persistent amenorrhea, despite normalised body weight.

Our study demonstrated that as many as $50 \%$ of women with persistent amenorrhea had normal body weight. By determining the levels of sex hormones, we found out that all these women had hypogonadotropic hypogonadism. The same test constellation (low levels of LH and oestradiol in blood) was confirmed in the majority of the patients in the acute period of the illness, during hospitalisation, as well as in our previous study on AN girls [3]. LH suppression results from dysregulation of $\mathrm{GnRH}$ pulses in AN patients. Clinical observations point to the fact that the extent of LH suppression does not depend on the duration of the illness and the degree of emaciation, and the return of menstruation does not demonstrate a simple dependency on body weight. Studies conducted in recent years allowed to identify $\mathrm{GnRH}$ pulsation regulators responsible for amenorrhea in women suffering from AN. Several studies point to the role of leptin and kisspeptin, important regulators of the reproductive function in women with functional hypothalamic amenorrhea [1]. Hypogonadotropic hypogonadism leads to hypoandrogenemia and consequently to hypoestrogenemia. Effects of testosterone deficits in women with anorexia nervosa are not fully understood. Cross-sectional studies demonstrate an inverse relationship between the level of androgens in blood and the severity of symptoms of depression and anxiety disorders in women with AN, irrespective of their body weight [1].

In compliance with the current DSM-5 criteria from 2013 [24], amenorrhea is not taken into account when diagnosing anorexia nervosa, one of the reasons being that in some women the menstrual cycle is normal and they still satisfy other axial 
diagnostic criteria of AN (loss of body weight and mental symptoms). Nevertheless, information on any menstrual disorders is important in the clinical practice as most often they result from lower levels of oestrogens in blood. The deficit of oestrogens is one of crucial factors responsible for reduced bone mineral density. Therefore, in order to treat AN, besides an increase of the body weight adequate to the needs, stabilisation of the general state of the patient, and resolution of mental issues, the return of regular menstruation and restoration of the reproductive capacity are necessary.

Recent years have seen many studies published in the available subject literature [18-23], including by Polish authors $[2,8,25,28]$, devoted to the incidence of body mineral density disorders, bone metabolism markers, the state of the skeleton, and the development of osteoporosis in girls suffering from AN. It is a known fact that bone mineral density disorders in such patients are the resultant of factors that impair bone formation and intensify bone resorption processes in the period of development of the peak bone mass. The pathogenesis and hormonal mechanisms leading to skeletal dysregulation and consequently to osteoporosis in women suffering from $\mathrm{AN}$ in adolescence are better and better understood [1, 29].

There are very few long-term prospective studies evaluating the state of the bone tissue in individuals with an early onset of AN. Misra et al. [30] conducted a prospective observation of BMD of the spine bones and of the total body in 34 girls with AN aged 12-18 (average age: $15.9 \pm 1.5$ ), performing measurements at the time of falling ill and after 6 and 12 months. They demonstrated significantly lower values of the BMD Z-score in AN patients, as compared to the group of 33 healthy girls $(p=0.0005)$. The return of menstruation 9 months after treatment commencement on average brough about stabilisation in terms of BMD values. In patients which did not have any weight gain or return of menstruation, the BMD values were still lowered. The authors conclude that each short-term body weight gain and return of menstruation in AN patients is accompanied by stabilisation of BMD values.

In our previous study [25] conducted prospectively 7.8 \pm 2.4 months after hospital admission in 10 girls with AN aged 11.5-18.1 (average age: $15.9 \pm 1.9$ ), we demonstrated reduced values of BMD as compared to the healthy population at the same age (average Z-score for the spine -1.28 , and for the total

\section{References}

1. Miller KK. Endocrine dysregulation in anorexia nervosa update. J Clin Endocrinol Metab 2011; 96: 2939-2949. doi: 10.1210/jc.2011-1222.

2. Horst-Sikorska W, Ignaszak-Szczepaniak M. The role of anorexia nervosa in secondary osteoporosis development with the risk for low energy fractures. Endokrynol Pol 2011; 62: 45-47.

3. Ziora K, Oświęcimska J, Dyduch A, et al. Frequency of hormonal disorders in anorectic girls. Endokrynol Ped 2006; 3: 9-16.

4. Meczekalski B, Podfigurna-Stopa A, Genazzani AR. Hypoestrogenism in young women and its influence on bone mass density. body -0.67$)$. These changes exhibited a tendency of progression in a follow-up examination (average Z-score: -1.46 and -0.79 , respectively).

This DEXA study, on the other hand, had been planned as an addition to the study devoted to the evaluation of long-term treatment results in women suffering from $A N$ in adolescence. It covered as many as 56 women 7 years on average after their hospitalisation, and its only goal was to assess the incidence of bone mineral density disorders. We observed that only $14 \%$ of women did not present any bone mineral density disorders in the DEXA scan of the spine and of total body, whereas in the vast majority of women (85.7\%), both already cured and still sick, we observed reduced levels of BMD.

Biller et al. [31] demonstrated that adult women with AN where the onset of the illness took place in adolescence, reached lower values of BMD as compared to the women where the illness began at a later age, even with a comparable duration of amenorrhea. Other authors [32] demonstrated, like we did, that lowered BMD values persist even years after reaching a normal body weight.

We are aware of certain limitations of our study. We did not investigate all factors that could affect menstrual disorders, such as diet, physical exercise, medications and vitamins taken currently or in the past. Likewise, we did not conduct a psychiatric examination nor psychological assessment. We based our efforts exclusively on subjective information (on the basis of the questionnaires). An objective assessment comprised anthropometric measurements, hormonal tests, and DEXA scans. This study supplemented the survey study devoted to long-term AN treatment results.

\section{Conclusions}

In almost $18 \%$ of women treated for anorexia nervosa in adolescence, disorders of the hormonal function of gonads persist, manifest as hypogonadotropic hypogonadism, despite normal body weight in $50 \%$ of them.

Bone mineral density is reduced in most women treated for anorexia nervosa in adolescence, which indicates the need to monitor the condition of the bones, an early introduction of prevention of osteopenia and osteoporosis since the onset of AN in order to prevent bone fractures in adulthood.
Gynecol Endocrinol 2010; 26: 6527. doi: 10.3109/09513590.2010. 486452.

5. Emanuela A, Lenzi GA, Migliaccio S. The pathophysiological basis of bone tissue alterations associated with eating disorders. Horm Mol Biol Clin Invest 2016; 28: 121-132. doi: 10.1515/hmbci-2016-0006.

6. Jagielska GW, Przedlacki J, Bartoszewicz Z, et al. Bone mineralization disorders as a complication of anorexia nervosa - etiology, prevalence, course and treatment. Psychiatr Pol 2016; 50: 509-520.

7. Donaldson AA, Gordon CM. Skeletal complications of eating disorders. Metabolism 2015; 64: 943-951. 
8. Ostrowska Z, Ziora K, Kos-Kudła B, et al. Melatonin, the RANKL/ RANK/OPG system and bone metabolizm in girls with anorexia nervosa. Endokryn Pol 2010; 61: 117-123.

9. Errichiello L, lodice D, Bruzzese D, et al. Prognostic factors and outcome in anorexia nervosa: follow-up study. Eat Weight Disord 2016, 21: 73-82. doi: 10.1007/s40519-015-0211-2

10. Strober M, Freeman R, Morrell W. The long-term course of severe anorexia nervosa in adolescents: Survival analysis of recovery, relapse, and outcome predictors over 10-15 years in a prospective study. Int J Eat Disord 1997; 22: 339-360. doi: 10.1002/(sici)1098108x(199712)22:4<339::aid-eat1>3.0.co;2-n.

11. Wentz E, Gillberg C, Gillberg IC, et al. Ten-year follow-up of adolescent-onset anorexia nervosa; psychiatric disorders and overall functioning scales. J Child Psychol Psychiatr 2001; 42: 613-622.

12. Steinhausen HC. The outcome of anorexia nervosa in the $20^{\text {th }}$ century. Am J Psychiatry 2002; 159: 1284-1293.

13. Kohmura $\mathrm{H}$, Miyake $\mathrm{A}$, Aono $\mathrm{T}$, et al. Restoration of reproductive function in patients with anorexia nervosa: a 10-year follow-up study. Eur J Obstet Gynecol Reprod Biol 1986; 22: 293-296. doi: 10.1016/0028-2243(86)90117-6.

14. Dempfle A, Herpertz-Dahlmann B, Timmesfeld N, et al. Predictors of the resumption of menses in adolescent anorexia nervosa. BMC Psychiatry 2013; 13: 308. doi: 10.1186/1471-244X-13-308.

15. Golden NH, Jacobson MS, Schebendach J, et al. Resumption of Menses in Anorexia Nervosa. Arch Pediatr Adolesc Med 1997; 151 : 16-21. doi: 10.1001/archpedi.1997.02170380020003.

16. Jacoangeli F, Staar Mezzasalma F, Fiori R, et al. Amenorrhea after weight recover in anorexia nervosa: Role of body composition and endocrine abnormalities. Eat Weight Disord 2006; 11: e20-6. doi: 10.1007/BF03327748.

17. Wiksten-Almströmer M, Hirschberg AL, Hagenfeldt K. Prospective follow-up of menstrual disorder in adolescence and prognostic values. Acta Obstet Gynecol Scand 2008; 87: 1162-1168. doi: 10.1080/00016340802478166.

18. Mumford J, Kohn M, Briody J, et al. Long-term Outcomes of Adolescent Anorexia Nervosa on Bone. J Adolesc Health 2019; 64: 305-310. doi: 10.1016/j.jadohealth.2018.07.025.

19. Carmo I, Mascarenhas M, Macedo A, et al. Study of bone density change in patients with anorexia nervosa. Eur Eat Disord Rev 2007; 15: 457-462. doi: 10.1002/erv.812.

20. Olmos JM, Valero C, del Barrio AG, et al. Time course of bone loss in patients with anorexia nervosa. Int J Eat Disord 2010; 43: 537-542.
21. Schulze UM, Schuler S, Schlamp D, et al. Bone mineral density in partially recovered early onset anorexic patients - a follow-up investigation. Child Adolesc Psychiatry Ment Health 2010; 4: 20. doi: 10.1186/1753-2000-4-20.

22. Achamrah N, Coëffier M, Jésus $P$, et al. Bone Mineral Density after Weight Gain in 160 Patients with Anorexia Nervosa. Front Nutr 2017; 4: 46. doi: 10.3389/fnut.2017.00046.

23. Hartman D, Crisp A, Rooney B, et al. Bone density of women who have recovered from anorexia nervosa. Int J Eat Disorder 2000; 28: 107-112. doi: 10.1002/(sici)1098-108x(200007)28:1<107::aideat13>3.0.co;2-m

24. American Psychiatric Association. Diagnostic and Statistical Manual of Mental Disorders (DSM-V). American Psychiatric Association, Washington DC 2013.

25. Oświęcimska J, Ziora K, Pluskiewicz W, et al. Ocena gęstości mineralnej kości oraz markerów metabolizmu kostnego u dziewcząt z jadłowstrętem psychicznym. Doniesienie wstępne. Endokrynol Ped 2004; 3: 21-32.

26. Frisch RE, McArthur JW. Menstrual cycles: fatness as determinant of minimum weight for height necessary for their maintenance or onset. Science 1974; 185: 949-951. doi: 10.1126/science.185.4155.949.

27. Winkler Al-D, Frolich JS, Schulpen M, et al. Body composition and menstrual status in adults with a history of anorexia nervosa-at what fat percentage is the menstrual cycle restored? Int J Eat Disord 2017; 50: 370-377. doi: 10.1002/eat.22600.

28. Oświęcimska J, Ziora K, Pluskiewicz W, et al. Skeletal status and laboratory investigations in adolescent girls with anorexia nervosa. Bone 2007; 41: 103-110. doi: 10.1016/j.bone.2007.03.018.

29. Fazeli PK, Klibanski A. Anorexia nervosa and bone metabolism. Bone 2014; 66: 39-45. doi: 10.1016/j.bone.2014.05.014

30. Misra M, Prabhakaran R, Miller KK, et al. Weight gain and restoration of menstruation as prognostic factors for changes in bone mineral density in adolescent girls with anorexia nervosa-1. J Clin Endocrinol Metab 2008; 93: 1231-1237. doi: 10.1210/jc.2007-1434.

31. Biller BM, Saxe V, Herzog DB, et al. Mechanisms of osteoporosis in adult and adolescent women with anorexia nervosa. J Clin Endocrinol Metab 1989; 68: 548-554. doi: 10.1210/jcem-68-3-548.

32. Mueller SM, Immoos M, Anliker E, et al. Reduced Bone Strength and Muscle Force in Women 27 Years After Anorexia Nervosa. J Clin Endocrinol Metab 2015; 100: 2927-2933. doi: 10.1210/jc.2015-1011. 